\title{
Association of 25-hydroxy-vitamin D levels with semen and hormonal parameters
}

\author{
Ahmad O Hammoud ${ }^{1}$, A Wayne Meikle ${ }^{2,3}$, C Matthew Peterson' ${ }^{1}$, Joseph Stanford ${ }^{4}$, Mark Gibson ${ }^{1}$ \\ and Douglas T Carrell ${ }^{1,5}$
}

Vitamin D levels have been linked to various health outcomes including reproductive disorders. The purpose of this study was to explore the association between serum vitamin D level (25-hydroxy-vitamin D, or 250HD) and semen and hormonal parameters. This is a cross-sectional study that included $\mathbf{1 7 0}$ healthy men recruited for the study of spermatogenesis from the general population. Men completed general and reproductive health questionnaires, and donated blood and semen samples. The main measures were hormonal (total and free testosterone, sex hormone-binding globulin, estradiol, follicle-stimulating hormone and luteinizing hormone) and semen parameters, adjusted $(n=147)$ for age, body mass index (BMI), season, alcohol intake and smoking, in relation to categories of vitamin D levels, determined a priori. The mean age of the study population was $29.0 \pm 8.5$ years and mean BMI was $24.3 \pm 3.2 \mathrm{~kg} \mathrm{~m}^{-2}$. The mean 250HD was $34.1 \pm 15.06 \mathrm{ng} \mathrm{ml}^{-1}$. BMI showed a negative association with $250 \mathrm{HD}$. Sperm concentration, sperm progressive motility, sperm morphology, and total progressively motile sperm count were lower in men with ' $250 \mathrm{HD} \geqslant 50 \mathrm{ng} \mathrm{ml}^{-1}$ ' when compared to men with ' $20 \mathrm{ng} \mathrm{ml}^{-1} \leqslant 250 \mathrm{HD}<50 \mathrm{ng} \mathrm{ml}^{-1}$ '. Total sperm count and total progressive motile sperm count were lower in men with ' $250 \mathrm{HD}<20 \mathrm{ng} \mathrm{ml}^{-1}$ ' when compared to men with ' $20 \mathrm{ng} \mathrm{ml}^{-1} \leqslant 250 \mathrm{HD}<50 \mathrm{ng} \mathrm{ml}^{-1}$ '. The adjusted means of various hormonal parameters did not show statistical difference in the different categories of 250HD. In conclusion, serum vitamin D levels at high and low levels can be negatively associated with semen parameters.

Asian Journal of Andrology (2012) 14, 855-859; doi:10.1038/aja.2012.77; published online 8 October 2012

Keywords: low semen count; obesity; semen parameters; vitamin D

\section{INTRODUCTION}

Low serum vitamin D levels are very prevalent, with an estimated $32 \%$ of healthy population in the United States being deficient in vitamin D. ${ }^{1}$ Vitamin D deficiency has been linked to various health disorders including bone health, cardiovascular, infectious, oncologic, musculoskeletal, neuropsychologic and reproductive disorders, as well as to overall mortality. ${ }^{2-9}$ While the role of vitamin D deficiency in reduced bone mass is evident, its relation to other health disorders is the subject of debate. ${ }^{7}$ A recent publication by the United States' Institute of Medicine (IOM), however, questioned the reported rates of vitamin $\mathrm{D}$ deficiency and insufficiency. The IOM proposed new guidelines regarding the intake of calcium and vitamin $\mathrm{D}$ and set new standards for serum vitamin D levels (25-hydroxy-vitamin D, or 25OHD). ${ }^{10}$ Animal studies suggested that vitamin D deficiency in male rats may affect spermatogenesis. ${ }^{11}$ The vitamin D receptor has been documented in human sperm ${ }^{12,13}$ and vitamin D metabolizing enzymes are found in the male reproductive system. ${ }^{14}$ Vitamin D levels have shown a positive correlation with serum androgen levels in men. ${ }^{15}$ These observations have led to the hypothesis that vitamin D levels may be associated with sperm parameters. Recently, Ramlau-Hansen et al. ${ }^{9}$ tested this hypothesis in a group of 307 men. Surprisingly, and contrary to the author's hypothesis, high levels of vitamin D were found to be associated with lower crude median total sperm count and percentage of normal morphology sperm, while low levels of vitamin D were not associated with sperm parameters, this relation was not statistically significant when corrected for the other confounding factors. ${ }^{9}$ The complete characterization of the association of vitamin D levels with the male reproductive function remains to be elucidated.

The purpose of our study was to explore the association between vitamin D levels (25OHD), with various semen and hormonal parameters in a group of healthy males recruited from the general population.

\section{MATERIAL AND METHODS}

Study population

In an Institutional Review Board approved protocol, 272 men were recruited for the study of spermatogenesis. These men were recruited through advertisement to participate in a larger study that aims to create a DNA, semen data and clinical information repository for the study of spermatogenesis in the general population. Targeted subjects were aged 18 years and older (range 18-67 years), from all ethnic background. Subjects were recruited by newspaper advertisement and fliers distributed and posted online. The majority of men that

${ }^{1}$ Division of Reproductive Endocrinology and Infertility, University of Utah, Salt Lake City, UT 84108, USA; ${ }^{2}$ Division of Endocrinology, Metabolism and Diabetes, Department of Internal Medicine, University of Utah School of Medicine, Salt Lake City, UT 84108, USA; ${ }^{3}$ ARUP Institute for Clinical and Experimental Pathology, Salt Lake City, UT 84108, USA; ${ }^{4}$ Department of Preventive and Family Medicine, University of Utah, Salt Lake City, UT 84108, USA and ${ }^{5}$ Department of Surgery (Urology) and Physiology, Andrology and IVF Laboratories, University of Utah, Salt Lake City, UT 84108, USA

Correspondence: Dr AO Hammoud (ahmad.hammoud@hsc.utah.edu)

Received: 29 April 2012; Revised: 12 June 2012; Accepted: 22 June 2012; Published online: 8 October 2012 
responded were residents of Salt Lake City, UT, USA and were of Caucasian background. After participation, subjects were compensated US $\$ 50.00$ for their time and travel. All men completed a detailed general health and reproductive health questionnaire, and donated one blood and semen samples for hormonal, DNA and sperm parameters analysis. Before presentation, men were asked to respect a period of abstinence between 2 and 5 days. The study questionnaires included detailed questions regarding alcohol and tobacco use, intake of supplements, and vitamin intake. This multifaceted, ongoing study provides serum for various hormonal tests based on the original volume of the serum sample and whether the sample has been utilized for previous analysis. For the current study, vitamin D levels were measured on 170 men. Men without vitamin D level testing $(n=102)$ did not differ from our study population in any of their demographic, hormonal and semen characteristics (data not shown). Vitamin D intake was evaluated through dietary questionnaires. After reviewing study subjects' histories, we found 18 participants with history of reproductive disorders that can affect hormonal or semen parameters (some participants had more than one problem): one case of testicular infection, one case of testicular mumps, nine cases of anabolic steroid intake, three cases of cryptorchidism, one vasectomy, three cases of varicocelectomy, three cases of non-defined infertility problems (participants responded by 'yes' to the question: Do you have any infertility problem?). For the descriptive analysis of study population including vitamin D levels, all 170 men were included. For the analysis of the relation of vitamin D and semen and hormonal parameters we excluded men with male factor infertility.

\section{Semen analysis}

Sperm parameters analyzed included: sperm concentration (million $\mathrm{ml}^{-1}$ ), progressive sperm motility (\%), sperm morphology (percent normal sperm head, \%), the total sperm count per ejaculate (million sperm) and the total progressive motile sperm count per ejaculate (million progressive motile sperm). Two experienced technicians operating under an active quality control program performed all analyses. The composite parameter (total progressive motile sperm count) was calculated using the following formula: total progressive motile sperm count $=$ semen volume $\times$ sperm concentration $\times$ percent progressive motile sperm. Total sperm count per ejaculate was calculated as: total sperm count $=$ ejaculate volume $\times$ sperm concentration. Total sperm count and total progressive motile sperm count correlate more accurately with male fertility than crude semen parameters. ${ }^{16,17}$ The University of Utah Andrology and Embryology Laboratories have employed the World Health Organization (WHO) 4th edition protocols with vigorous internal quality controls, as well have an extensive training and continuing education program to assure the quality of the semen analysis results. Additionally, proficiency testing is performed for semen analysis parameters using the College of American Pathologist and American Association of Bioanalysts programs. The laboratory has made minor adjustments to the WHO 4th edition protocols, but has shown that the deviations do not show significant changes in values. The method for sperm morphology is a modification of the WHO 4th method for morphology analysis. Each modification was internally validated. This laboratory has shown the morphology values from this modified technique to correlate with fertility outcome, as well as in vitro fertilization success rates. ${ }^{18-21}$

\section{Metabolic and hormonal analysis}

Study participants underwent a morning venous blood draw after 12-h overnight fasting. The following were measured: total testosterone using an electrochemiluminescence immunoassay (ECLIA) (Elecsys Testosterone Kit; Roche Diagnostics, Indianapolis, IN, USA; sensitivity (Se): 1.1 ; coefficient of variation (CV) \%: $1.0 \%-6.7 \%)$ ), sex hormone-binding globulin (SHBG) via ECLIA (Elecsys SHBG Kit; Roche Diagnostics; Se: 0.01 ; CV\%: $1.0 \%-1.1 \%$ ), follicle-stimulating hormone (FSH) by ECLIA (Elecsys FSH Kit; Roche Diagnostics; Se: 0.0036; CV\%: 1.0\%-1.3\%), estradiol using ECLIA(Architect Kit; Abbott Diagnostics Laboratories, Abbott Park, IL, USA; Se: 10; CV\%: 2.4\%-6.2\%) and luteinizing hormone through ECLIA (Elecsys LH Kit; Roche Diagnostics; Se: 0.011; CV\%: 1.2\%-1.5\%). Free testosterone was calculated using the following formula: $\mathrm{FH}=([\mathrm{H}]-(\mathrm{N} \times[\mathrm{FH}]))$ / $(\mathrm{Kt} \times[\mathrm{SHBG}-[\mathrm{H}]+\mathrm{N} \times[\mathrm{FH}]])$ (where $\mathrm{FH}$ is the free hormone (testosterone) concentration, $\mathrm{H}$ is total hormone (testosterone) concentration and $\mathrm{Kt}$ is the association constant of SHBG for testosterone) and $\mathrm{N}=\mathrm{Ka} \times \mathrm{Ca}+1$ (where $\mathrm{Ka}$ is the association constant of albumin to testosterone and $\mathrm{Ca}$ is the albumin concentration). ${ }^{22}$ Serum vitamin $\mathrm{D}$ levels were assessed by measuring serum $25 \mathrm{OHD}$ levels using chemiluminesence immunoassay (Liaison Assay; Diasorin; Se: 4; CV\%: 4.8\%$5.5 \%)$. This assay accurately quantifies the sum of 25-hydroxy-vitamin $\mathrm{D}_{3}$ and 25-hydroxy-vitamin $\mathrm{D}_{2}$. It has been validated and compared with liquid chromatography/mass spectrometry in the laboratory that analyzed the samples. ${ }^{23}$ 25OHD levels were divided a priori into three categories: $25 \mathrm{OHD}$ less than $20 \mathrm{ng} \mathrm{ml}^{-1}$ (vitamin D deficiency), 25OHD between $20-50 \mathrm{ng} \mathrm{ml}^{-1}$ and $25 \mathrm{OHD}$ equal or above $50 \mathrm{ng} \mathrm{ml}^{-1}$. The last category was based on the IOM report that described poor outcome for some health disorders in the presence of high vitamin D levels. ${ }^{7,10}$ All hormonal analyses were performed at the Associated Regional University Pathologists Institute for Clinical and Experimental Pathology. Associated Regional University Pathologists is a national reference laboratory located in Salt Lake City, UT, USA.

\section{Statistical analysis}

Body mass index (BMI) was divided into three categories according to the National Institutes of Health, National Heart Lung and Blood Institute classification: normal weight (BMI $\leqslant 25 \mathrm{~kg} \mathrm{~m}^{-2}$ ), overweight $\left(25 \mathrm{~kg} \mathrm{~m}^{-2}<\mathrm{BMI}<30 \mathrm{~kg} \mathrm{~m}^{-2}\right)$ and obese $\left(\mathrm{BMI} \geqslant 30 \mathrm{~kg} \mathrm{~m}^{-2}\right)$. These categories correspond to the WHO classes of BMI: normal, pre-obese and obese, respectively.

For descriptive statistics, mean \pm s.d. and median (fifth and ninetyfifth percentiles) were reported when appropriate. When reported for test statistics, mean was reported as mean \pm s.e. One-way ANOVA was used to compare unadjusted means of vitamin D between the BMI categories. Multiple linear models were built to assess the association between vitamin D levels and semen parameters. These models included factors correlated to both vitamin D levels and semen parameters, thus fulfilling the definition of confounders. Factors that are correlated to either vitamin D levels or semen parameters but not to both were not included. In the final model, the following factors were retained: age, BMI, season, alcohol intake and smoking. The definition of season was done a priori and was based on two seasons per year, from April to September and October to March. The smoking and alcohol utilization in this population were low, so these variables were dichotomized based on current use. Abstinence was partially reported and was not correlated to vitamin D levels, subsequently, did not meet the criteria for a confounding factor, and was not included in the model. When reported, the average abstinence was $3.1 \pm 1.8$ days (mean \pm s.d.), consistent with the study requirement. The available abstinence data were not different in the study groups. Because of the non-parametric nature of semen parameters, semen analysis data were cube root transformed for this analysis. ${ }^{24}$ Geometric means and 
95\% confidence intervals were reported for the association between vitamin D and semen parameters. Means and s.e. were reported for association between vitamin D levels and hormonal parameters. The Statistical Package for the Social Sciences version 20.0 (SPSS Inc., Chicago, IL, USA) was used for statistical analysis. Statistical significance was set at $P<0.05$.

\section{RESULTS}

The age in our study population was $29.0 \pm 8.5$ years (mean \pm s.d.) and mean BMI was $24.3 \pm 3.2 \mathrm{~kg} \mathrm{~m}^{-2}$. The mean $25 \mathrm{OHD}$ level was $34.1 \pm 15.1 \mathrm{ng} \mathrm{ml}^{-1}$. The distribution of different 25OHD categories was as follow: $25 \mathrm{OHD}<20 \mathrm{ng} \mathrm{ml}^{-1}: 12.4 \%(n=21) ; 20 \mathrm{ng} \mathrm{ml}^{-1} \leqslant$ $25 \mathrm{OHD}<50 \mathrm{ng} \mathrm{ml}^{-1}: 75.2 \%(n=128) ; 25 \mathrm{OHD} \geqslant 50 \mathrm{ng} \mathrm{ml}^{-1}: 12.4 \%$ $(n=21)$.

The mean values of $25 \mathrm{OHD} \pm$ s.e. in the different BMI categories were as follow (after exclusion of participants taking vitamin $\mathrm{D}(n=5)$ and with no reported BMI $(n=3)$ : normal weight: $36.4 \pm 1.6 \mathrm{ng} \mathrm{ml}^{-1}$ $(n=100)$; overweight: $32.3 \pm 1.8 \mathrm{ng} \mathrm{ml}^{-1}(n=54)$; obese: $22.2 \pm$ $4.1 \mathrm{ng} \mathrm{ml}^{-1}(n=8)$ (ANOVA: $P=0.016$, Figure 1).

After excluding men with male factor infertility, the remaining 152 participants did not have any known factors potentially influencing their reproductive function. The median (5\%-95\%) of sperm concentration was 69.9 million $\mathrm{ml}^{-1}\left(4.2-216.3\right.$ million $\left.\mathrm{ml}^{-1}\right)$, the median of percent motile sperm was $45 \%(11.3 \%-82.5 \%)$, the median of percent normal sperm head was $29 \%(6 \%-51 \%)$, the median of total progressive motile sperm was 78.0 million motile sperm (0.8-398.4 million) and the median of total sperm was 136.6 million sperm (4.8619.0 million).

The relation between $25 \mathrm{OHD}$ and various hormonal and semen parameters was corrected for age, BMI, season, alcohol intake and smoking. Three men had missing BMI and two others were missing information for the other confounding factors and were dropped from the multiple linear model, and 147 men had enough information to be included. The distribution of the adjusted geometric means of various semen parameters is given in Table $\mathbf{1}$. The percent normal sperm head, percent progressive motile sperm and sperm concentration were lower in men with $25 \mathrm{OHD} \geqslant 50 \mathrm{ng} \mathrm{ml}^{-1}(P<0.05)$ when compared to men with $20 \mathrm{ng} \mathrm{ml}^{-1} \leqslant 25 \mathrm{OHD}<50 \mathrm{ng} \mathrm{ml}^{-1}$. The total progressive sperm count showed lower values in both categories $25 \mathrm{OHD}<20 \mathrm{ng} \mathrm{ml}^{-1}$ $(P<0.05)$ and $25 \mathrm{OHD} \geqslant 50 \mathrm{ng} \mathrm{ml}^{-1}(P<0.05)$ when compared to $20 \mathrm{ng} \mathrm{ml}^{-1} \leqslant 25 \mathrm{OHD}<50 \mathrm{ng} \mathrm{ml}^{-1}$. Total sperm count showed lower values in men with $25 \mathrm{OHD}<20 \mathrm{ng} \mathrm{ml}^{-1}$ when compared to men with

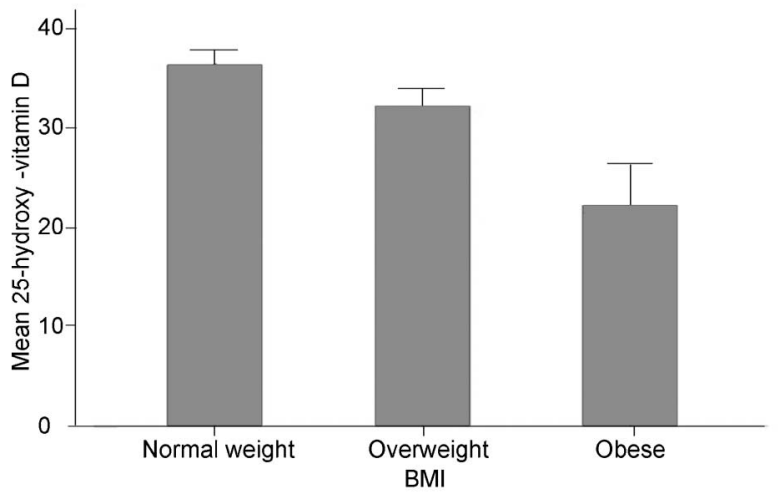

Figure 1 Mean levels of 25-hydroxy-vitamins $\mathrm{D}$ levels (ng $\mathrm{ml}^{-1}$ ) per BMI category in a group of men recruited form the general population. Vitamin D levels are lower in overweight $(n=54)$ and obese men $(n=8)$ when compared to normal weight men ( $n=100$ ). (ANOVA: $P=0.016$ ). BMI, body mass index.
$20 \mathrm{ng} \mathrm{ml}^{-1} \leqslant 25 \mathrm{OHD}<50 \mathrm{ng} \mathrm{ml}^{-1}(P<0.05)$. To note, that sperm volume was lower in men with $25 \mathrm{OHD}<20 \mathrm{ng} \mathrm{ml}^{-1}$, but not statistically different from the other categories (data not shown).

There was no statistical difference between the mean hormonal values in the different categories of 25OHD (Table 2).

\section{DISCUSSION}

Our data show that serum $25 \mathrm{OHD}$ is reduced proportionally to increased weight in men. $25 \mathrm{OHD}$ was also found to be associated with semen parameters after correcting for age, BMI, season, alcohol intake and smoking. Men with $25 \mathrm{OHD}$ between 20 and $50 \mathrm{ng} \mathrm{ml}^{-1}$ exhibited maximal values of semen parameters. Men with a $25 \mathrm{OHD}$ above $50 \mathrm{ng} \mathrm{ml}^{-1}$ exhibited lower percent normal sperm head, percent progressive motile sperm, sperm concentration and total progressive motile sperm count. Men with $25 \mathrm{OHD}$ below $20 \mathrm{ng} \mathrm{ml}^{-1}$ showed lower total sperm count and total progressive motile sperm. 25OHD was not correlated to reproductive hormone values in our population, suggesting that, the deleterious effect of high and low 25OHD on sperm parameters, may not be mediated by reproductive hormones. Ramlau-Hansen et al. ${ }^{25}$ found lower crude median total sperm count and percentage of normal morphology sperm with higher vitamin D. This relation was attenuated and became not significant after correction for confounding factors. Our data correlated with their data in terms of the lower values of certain semen parameters in men with high levels of 25OHD; however, our data was significant even after correction for age, BMI, season, smoking and alcohol use. For their study, $94 \mathrm{nmol} \mathrm{l}^{-1}$ was used as the cutoff value for 'high vitamin D', which corresponds to $37.7 \mathrm{ng} \mathrm{ml}^{-1}$. 9 Similar to our findings, RamlauHansen et al..$^{25}$ did not find correlation between serum vitamin D and hormonal parameters. Our study and the study by Ramlau-Hansen et al. ${ }^{10}$ demonstrated that a possible male reproductive toxicity or no benefit associated with serum vitamin $\mathrm{D}$ is observed at much lower levels than previously thought. These results are in parallel to studies reporting increased overall mortality in association with serum vitamin $\mathrm{D}$ level occurring at levels of $75-120 \mathrm{nmol} \mathrm{l}^{-1}\left(30-50 \mathrm{ng} \mathrm{ml}^{-1}\right) .^{10}$

Blomberg Jensen et al. ${ }^{26}$ found that low vitamin D levels were correlated with reduced sperm motility. ${ }^{26}$ In the study by Blomberg Jensen et al., high vitamin D levels did not have a negative effect on sperm parameters, but the authors used the threshold of $75 \mathrm{nmol} \mathrm{l}^{-1}$ which is equal to only $30 \mathrm{ng} \mathrm{ml}^{-1} \cdot{ }^{26}$ In our paper, low levels of vitamin D were associated with lower total progressive motile sperm count and lower total sperm count, but were not associated with sperm concentration, progressive motility or morphology. Taken together, the previous results and ours suggest a possible inverted ' $U$ shaped' relation of vitamin D to sperm parameters. ${ }^{10,26}$

Evidence is accumulating of a role for vitamin $\mathrm{D}$ in the reproductive function in males and females. Animal studies have shown that vitamin D plays a role in male reproductive function and vitamin D deficiency may be associated with altered semen parameters. This role for vitamin D in reproduction has been suspected since $1979 .{ }^{27}$ Rats fed a vitamin D-deficient diet showed a $45 \%$ reduction in successful mating when compared with another group fed a vitamin D-supplemented diet. ${ }^{28}$ In female rats, a diet deficient in vitamin $\mathrm{D}$ caused a $75 \%$ reduction in overall fertility and a $30 \%$ reduction in litter size. $^{29}$ Vitamin D supplementation successfully restored fertility in male and female rats previously fed on a diet depleted of vitamin D. ${ }^{29,30}$ Calcium supplementation without correcting vitamin D also restored the male rat fertility, ${ }^{30}$ suggesting that vitamin $\mathrm{D}$ deficiency may alter reproductive function through a calcium-dependent mechanism. In male rats, Vitamin D deficiency was shown to be associated 
Table 1 Adjusted means (95\% confidence interval) of hormonal parameters per category of serum vitamin D. The general linear model adjusted for age, BMI, season, alcohol intake and smoking (semen parameters were cube root transformed for this analysis)

\begin{tabular}{|c|c|c|c|}
\hline & $250 H D<20 \mathrm{ng} \mathrm{m}^{-1}(\mathrm{n}=19)$ & 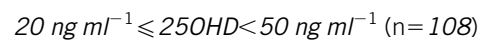 & $250 H D \geqslant 50 n g ~ m l^{-1}(n=20)$ \\
\hline Sperm concentration (million $\mathrm{ml}^{-1}$ ) & $52.1(30.2-82.5)$ & $84.0^{a}(70.3-99.3)$ & $46.7(27.2-73.9)$ \\
\hline Percent progressive motile sperm (\%) & $45.5(34.9-58.1)$ & $52.6^{\mathrm{a}}(47.6-58.0)$ & $38.4(29.3-49.2)$ \\
\hline Percent normal sperm heads (\%) & $20.1(13.5-28.6)$ & $27.4^{\mathrm{a}}(23.8-31.3)$ & $18.0(12.1-25.6)$ \\
\hline Total sperm count (million sperm) & $85.1(42.3-149.9)$ & $178.6^{\mathrm{b}}(145.6-216.3)$ & $110.2(60.1-182.4)$ \\
\hline
\end{tabular}

Abbreviations: BMI, body mass index; 250HD, 25-hydroxy-vitamin D levels.

a $P<0.05$, compared with $250 \mathrm{HD} \geqslant 50 \mathrm{ng} \mathrm{ml}^{-1}$.

${ }^{\mathrm{b}} \mathrm{P}<0.05$, compared with $250 \mathrm{HD}<20 \mathrm{ng} \mathrm{ml}^{-1}$.

with lower sperm count in the testis and epididymis, a finding that improved after vitamin D supplementation. ${ }^{11}$ Vitamin D receptor null mice show reduced aromatase activity in both males and females, and gonadal insufficiency with hypergonadotropic hypogonadism. ${ }^{31}$

Recently, Corbett et al. ${ }^{12}$ described the presence of vitamin D receptor in human sperm. This finding was also described by Aquilla et al. ${ }^{13}$ Vitamin D receptor was found through immunohystochemistry on the sperm head (nucleus) and mid piece. ${ }^{12}$ This finding was confirmed by Blomberg Jensen et al. ${ }^{14}$ who found vitamin D receptor, as well as vitamin D metabolizing enzymes in round and elongated spermatids, vesicles within the caput epididymis, and glandular epithelium of cauda epididymis, seminal vesicles and the prostate. In ejaculated mature sperm, vitamin D receptor expression and some vitamin D metabolizing enzymes were located in the neck and midpiece. ${ }^{14} \mathrm{An}$ in vitro component of the study showed that activated vitamin $\mathrm{D}(1-25)$ $\mathrm{OH}$ vitamin D 3 increased the intracellular calcium concentration, increased sperm motility and additionally induced the acrosome reaction. ${ }^{26}$ The negative relation between high levels of vitamin D and semen parameters in our data and in the crude analysis by RamlauHansen et al. ${ }^{25}$ can be explained by the experimental finding of Aquila et al. ${ }^{13}$ who explored the effect of vitamin D on intracellular calcium, sperm motility and acrosin reaction. In their study, the effect of increasing dose of vitamin $\mathrm{D}$ on these measures flattened and almost became negative at higher concentrations of vitamin $\mathrm{D}$. One also may speculate on whether high levels of vitamin D levels can induce alterations in the systemic or local calcium and zinc levels, both known to play a role in spermatogenesis. ${ }^{32,33}$

Our study has some limitations, vitamin D deficiency in our population was $12.4 \%$, slightly lower than what was previously described for a healthy population $(15 \%-40 \%){ }^{34}$ This could be attributed to the lower number of obese men recruited for this study (4\%) when compared with the national average in adult men $(32.2 \%) .{ }^{35} \mathrm{We}$ showed in this study that vitamin D levels are negatively correlated to weight. Vitamin D is fat soluble and levels have been shown to be lower in obese subjects. ${ }^{36}$ The lower levels of vitamins D in obese men add another layer of complexity to the relationship between obesity and male infertility. ${ }^{37}$ It remains to be demonstrated whether vitamin D levels are part of the negative effect of obesity on male fertility. In this study, testicular volume, a variable correlated to semen quality, was not evaluated. This omission, however, is unlikely to affect the results, as testicular volume is an intermediate variable in the evaluation of semen quality. Abstinence data were not collected for all participants. The study design stressed on getting the semen samples within the WHO accepted abstinence criteria. The partially reported abstinence does not bias our results for the following reasons:

1. The available abstinence intervals were not statistically different between the study groups.

2. Abstinence, while it can be correlated to semen parameters, was not found to be correlated to vitamin D levels in neither of the previously published articles by Ramlau-Hansen et al. ${ }^{25}$ and Blomberg Jensen et al. ${ }^{14,26}$ and subsequently, abstinence is not a true confounder in this relation.

Another limitation is the lower number of participants; however, this does not appear to have affected the results, since statistical significance was achieved after correcting for confounding factors. The unexpected finding in this study calls for more studies that included larger numbers of participant with more men in either the high or low vitamin D categories and studies of the effect of vitamin D supplementation on semen analysis to demonstrate causality. Last, each participant provided one semen sample, which does not account for the previously reported intra-individual variation in semen quality. ${ }^{38}$

In conclusion, our study showed a relation between vitamin D levels and semen parameters. Further studies are required to elucidate the pathophysiology of this relation, its modulation by obesity in men and its relation to the overall male fertility.

Table 2 Adjusted mean (s.e.) of hormonal parameters per category of serum vitamin D. The general linear model adjusted for age, BMI, season, alcohol intake and smoking. None of the comparisons were statistically different

\begin{tabular}{|c|c|c|c|}
\hline & $250 \mathrm{HD}<20 \mathrm{ng} \mathrm{m}^{-1}(\mathrm{n}=19)$ & 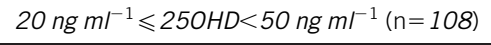 & 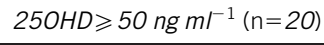 \\
\hline $\mathrm{FSH}\left(\mathrm{IU} \mathrm{I^{-1 } )}\right.$ & $3.1 \pm 0.41$ & $3.7 \pm 0.17$ & $4.0 \pm 0.40$ \\
\hline $\mathrm{LH}\left(I \cup \mathrm{I}^{-1}\right)$ & $3.9 \pm 0.43$ & $4.6 \pm 0.18$ & $5.1 \pm 0.42$ \\
\hline Total testosterone ( $\mathrm{ng} \mathrm{dl}^{-1}$ ) & $609.1 \pm 44.81$ & $583.0 \pm 18.74$ & $544.0 \pm 43.84$ \\
\hline Free testosterone $\left(\mathrm{pg} \mathrm{ml}^{-1}\right)$ & $114.9 \pm 7.82$ & $114.9 \pm 3.27$ & $105.0 \pm 7.65$ \\
\hline Estradiol (pg ml $\mathrm{I}^{-1}$ ) & $26.2 \pm 5.41$ & $31.2 \pm 2.10$ & $27.8 \pm 4.86$ \\
\hline
\end{tabular}

Abbreviations: BMI, body mass index; FSH, follicle-stimulating hormone; LH, luteinizing hormone. 


\section{AUTHOR CONTRIBUTIONS}

$\mathrm{AOH}, \mathrm{DTC}$ contributed to subjects recruitment, data analysis and manuscript preparation. AWM contributed in vitamin D and hormonal testing and data analysis and manuscript preparation. CMP, JS and MG contributed to data analysis and manuscript preparation.

\section{COMPETING FINANCIAL INTERESTS}

All authors declare that there are no competing financial interests.

1 Holick MF, Binkley NC, Bischoff-Ferrari HA, Gordon CM, Hanley DA et al. Evaluation, treatment, and prevention of vitamin d deficiency: an Endocrine Society Clinical Practice Guideline. J Clin Endocrinol Metab 2011; 96: 1911-30.

2 Adams JS, Hewison M. Update in vitamin D. J Clin Endocrinol Metab 2010; 95: 4718.

3 Baker AM, Haeri S, Camargo CA Jr, Espinola JA, Stuebe AM. A nested case-control study of midgestation vitamin D deficiency and risk of severe preeclampsia. J Clin Endocrinol Metab 2010; 95: 5105-9.

4 Faserl K, Golderer G, Kremser L, Lindner H, Sarg B et al. Polymorphism in vitamin Dbinding protein as a genetic risk factor in the pathogenesis of endometriosis. J Clin Endocrinol Metab 2011; 96: E233-41.

5 Gallagher JC, Sai AJ. Vitamin D insufficiency, deficiency, and bone health. J Clin Endocrinol Metab 2010; 95: 2630-3.

6 Osei K. 25-OH vitamin D: is it the universal panacea for metabolic syndrome and type 2 diabetes? J Clin Endocrinol Metab 2010; 95: 4220-2.

7 Ross AC, Manson JE, Abrams SA, Aloia JF, Brannon PM et al. The 2011 report on dietary reference intakes for calcium and vitamin $D$ from the institute of medicine: what clinicians need to know. J Clin Endocrinol Metab 2011; 96: 53-8.

8 Ward KA, Das G, Roberts SA, Berry JL, Adams JE et al. A randomized, controlled trial of vitamin $D$ supplementation upon musculoskeletal health in postmenarchal females. J Clin Endocrinol Metab 2010; 95: 4643-51.

9 Ramlau-Hansen CH, Moeller UK, Bonde JP, Olsen J, Thulstrup AM. Are serum levels of vitamin $D$ associated with semen quality? Results from a cross-sectional study in young healthy men. Fertil Steril 2011; 95: 1000-4.

10 Ross AC, Taylor CL, Yaktine AL, Del Valle HB, editors. Institute of Medicine (US Committee to Review Dietary Reference Intakes for Vitamin D and Calcium. Washington (DC): The National Academies Press; 2011.

11 Sood S, Reghunandanan R, Reghunandanan V, Marya RK, Singh PI. Effect of vitamin $\mathrm{D}$ repletion on testicular function in vitamin D-deficient rats. Ann Nutr Metab 1995; 39: 95-8.

12 Corbett ST, Hill O, Nangia AK. Vitamin D receptor found in human sperm. Urology 2006; 68: 1345-9.

13 Aquila S, Guido C, Middea E, Perrotta I, Bruno R et al. Human male gamete endocrinology: 1alpha, 25-dihydroxyvitamin $\mathrm{D}_{3}\left(1,25(\mathrm{OH}) 2 \mathrm{D}_{3}\right)$ regulates different aspects of human sperm biology and metabolism. Reprod Biol Endocrinol 2009; 7: 140 .

14 Blomberg Jensen M, Nielsen JE, Jorgensen A, Rajpert-De Meyts E, Kristensen DM et al. Vitamin $\mathrm{D}$ receptor and vitamin $\mathrm{D}$ metabolizing enzymes are expressed in the human male reproductive tract. Hum Reprod 2010; 25: 1303-11.

15 Wehr E, Pilz S, Boehm BO, Marz W, Obermayer-Pietsch B. Association of vitamin D status with serum androgen levels in men. Clin Endocrinol (Oxf) 2010; 73: 243-8.
16 Miller DC, Hollenbeck BK, Smith GD, Randolph JF, Christman GM et al. Processed total motile sperm count correlates with pregnancy outcome after intrauterine insemination. Urology 2002; 60: 497-501.

17 Amann RP. Considerations in evaluating human spermatogenesis on the basis of total sperm per ejaculate. J Androl 2009; 30: 626-41.

18 Hammoud AO, Griffin J, Meikle AW, Gibson M, Peterson CM et al. Association of aromatase (TTTAn) repeat polymorphism length and the relationship between obesity and decreased sperm concentration. Hum Reprod 2010; 25: 3146-51.

19 Hammoud AO, Wilde N, Gibson M, Parks A, Carrell DT et al. Male obesity and alteration in sperm parameters. Fertil Steril 2008; 90: 2222-5.

20 Jenkins TG, Aston KI, Carrell DT. Supplementation of cryomedium with ascorbic acid2-glucoside (AA2G) improves human sperm post-thaw motility. Fertil Steril 2011; 95 2001-4.

21 Nanassy L, Liu L, Griffin J, Carrell DT. The clinical utility of the protamine 1/protamine 2 ratio in sperm. Protein Pept Lett 2011; 18: 772-7.

22 Vermeulen A, Goemaere S, Kaufman JM. Testosterone, body composition and aging. J Endocrinol Invest 1999; 22: 110-6.

23 Kushnir MM, Ray JA, Rockwood AL, Roberts WL, La'ulu SL et al. Rapid analysis of 25 hydroxyvitamin $D_{2}$ and $D_{3}$ by liquid chromatography-tandem mass spectrometry and association of vitamin $\mathrm{D}$ and parathyroid hormone concentrations in healthy adults. Am J Clin Pathol 2010; 134: 148-56.

24 Handelsman DJ. Optimal power transformations for analysis of sperm concentration and other semen variables. J Androl 2002; 23: 629-34.

25 Ramlau-Hansen CH, Moeller UK, Bonde JP, Olsen J, Thulstrup AM. Are serum levels of vitamin $\mathrm{D}$ associated with semen quality? Results from a cross-sectional study in young healthy men. Fertil Steril 2011; 95: 1000-4.

26 Blomberg Jensen M, Bjerrum PJ, Jessen TE, Nielsen JE, Joensen UN et al. Vitamin D is positively associated with sperm motility and increases intracellular calcium in human spermatozoa. Hum Reprod 2011; 26: 1307-17.

27 Halloran BP, DeLuca HF. Vitamin D deficiency and reproduction in rats. Science 1979; 204: 73-4.

28 Kwiecinski GG, Petrie GI, DeLuca HF. Vitamin D is necessary for reproductive functions of the male rat. J Nutr 1989; 119: 741-4.

29 Kwiecinksi GG, Petrie GI, DeLuca HF. 1,25-Dihydroxyvitamin $D_{3}$ restores fertility of vitamin D-deficient female rats. Am J Physiol 1989; 256: E483-7.

30 Uhland AM, Kwiecinski GG, DeLuca HF. Normalization of serum calcium restores fertility in vitamin D-deficient male rats. J Nutr 1992; 122: 1338-44.

31 Kinuta K, Tanaka H, Moriwake T, Aya K, Kato S et al. Vitamin D is an important facto in estrogen biosynthesis of both female and male gonads. Endocrinology 2000; 141: 1317-24.

32 Mendoza FJ, Perez-Marin CC, Garcia-Marin L, Madueno JA, Henley C et al Localization, distribution and function of the calcium-sensing receptor in sperm. J Androl 2012; 33: 96-104.

33 Ebisch IM, Pierik FH, DE Jong FH, Thomas CM, Steegers-Theunissen RP. Does folic acid and zinc sulphate intervention affect endocrine parameters and sperm characteristics in men? Int J Androl 2006; 29: 339-45.

34 Tangpricha V, Pearce EN, Chen TC, Holick MF. Vitamin D insufficiency among free living healthy young adults. Am J Med 2002; 112: 659-62.

35 Flegal KM, Carroll MD, Ogden CL, Curtin LR. Prevalence and trends in obesity among US adults, 1999-2008. JAMA 2010; 303: 235-41.

36 Grethen $\mathrm{E}$, McClintock R, Gupta CE, Jones R, Cacucci BM et al. Vitamin d and hyperparathyroidism in obesity. J Clin Endocrinol Metab 2011; 96: 1320-6.

37 Hammoud AO, Wilde N, Gibson M, Parks A, Carrell DT et al. Male obesity and alteration in sperm parameters. Fertil Steril 2008; 90: 2222-5.

38 Hammoud AO, Gibson M, Peterson MC, Carrell DT. Effect of sperm preparation techniques by density gradient on intra-individual variation of sperm motility. Arch Androl 2007; 53: 349-51. 